\title{
A report of an elective to the Hospital for Sick Children and Bloorview Macmillan Centre, Toronto.
}

\section{R. McAndrew,}

The Department of Dentistry based at the Hospital for Sick Children and Bloorview MacMillan Centre in Toronto is unique. It provides treatment for cleft lip and palate patients and all forms of specialist dental treatment to children and adolescents resident in Ontario. The quality of service provided by the department has been externally recognised and validated through an ISO 9002 award (February 1999). At that time, it was the first Dental Clinic in North America to receive the ISO 9002 standard.' In addition, the American Cleft Palate-Craniofacial Association has recognised the department for its organisation and contributions in the field of cleft lip and palate and craniofacial surgery.

A $s$ a senior registrar in restorative denAtistry, I was privileged to visit the Hospital for Sick Children in Toronto under the supervision of Dr. R P Carmichael, Head of Prosthodontic Services in the Department of Dentistry, (Figure 1). I found it interesting to have witnessed a multi-disciplinary team providing outstanding patient care through mainly public funds. As a result, my outlook and perceptions towards the way that specialist services can or should be provided for dental patients in the United Kingdom has been altered radically following my visit to Toronto.

The provision for, and use of, recognised specialist services in Toronto helped reinforce my belief that high quality patient care can be delivered in the right environment and with the right team. Obviously there are differences in the health care systems of the UK and Canada. For some patients and certain items of service - dental treatment under NHS terms and regulations is free in the UK. In Canada, the majority of dental treatment is paid for on a private basis or through insurance schemes. However, there are exceptions. The Department

${ }^{1}$ Robert McAndrew, Directorate of Adult Dental Health, University Dental Hospital of Wales, Heath Park,Cardiff, Wales CF14 4XY

E-mail:mcandrew@cardiff.ac.uk

REFEREED PAPER

Received 20.05.99; Accepted 31.07.00

( $)$ British Dental Journal 2000; 189: xx-xx of Dentistry at HSC is one of those exceptions.

A staff of over 100 provides 24-hour dental emergency and ambulatory clinic treatment for patients referred by dentists and dental specialists throughout Canada. The department treats more than 20,000 children annually, and provides the majority of dental care to patients registered with the Canadian Ministry of Health's programme for the treatment and rehabilitation of patients with cleft lip and palate and other major dental disfigurements (Figures 2 and 3).
For providing dental services to the group of patients mentioned, the department receives a 75 per cent subsidy towards the total running costs from the Ministry; the remaining 25 per cent being paid by the parents or guardians of patients entering the programme. Should it be necessary, tailored payment plans are available — not all insurance companies pay out for what can be considered as cosmetic work.

I was not surprised to observe that only the best treatment regimes were proposed and paid for. Who would not want the best for their child? The department's philosophy of total patient care through childhood and into adolescence, as practised in the UK, is something that I felt has to be applauded; albeit in this case to a limited number of patients.

Interestingly, although an employee of the Department, Dr Carmichael was not

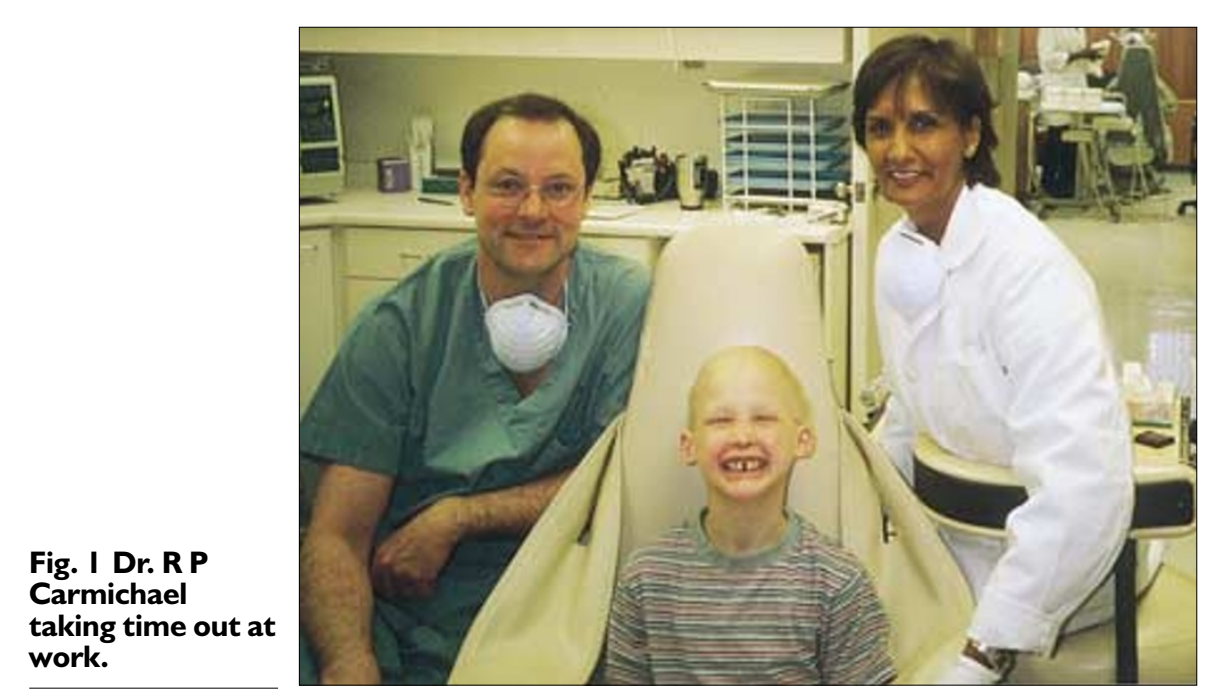

salaried directly to the unit but essentially employed as a private contractor and prosthodontic specialist. Where it is feasible, practical and desirable other dental specialists provide services for patients in the programme nearer their homes; the department's team acting as an organiser and facilitator of treatment. This seems a very sensible approach, especially when you con- 
sider the size of Ontario and that a 4 to 5 hour drive to the department to receive treatment is common.

All dentists taking part in the programme are recognised for their specialist services by being registered on the States' specialist list. I sometimes wonder if a similar system would work in the UK. Perhaps, following suggestions resulting from the Clinical Standards Advisory Group ${ }^{2}$ report and the establishment of specialist lists in the UK, this is something that will be practised nearer home in the future. Such a scheme may be workable for major disorders of dental development as well as cleft lip and palate services.

My experiences with the ISO 9002 standard ${ }^{3}$ suggest that adopting quality standards will fundamentally change the delivery of dental care, and the face of dental practice, in the UK in the not too distant future, whether or not it is specialist based. The fact that an ISO 9002 award has been awarded to a dental department in a health care institution goes to show that it is possible for such places to set and achieve the exacting standards required to satisfy such an externally validated process. In the UK the Investors in People standard is also obviously achieving the same results for many dental practices at the moment.

In order to satisfy all concerned, it is of fundamental importance that the standards set are of the highest calibre. At HSC the standards were assimilated from a wide variety of sources e.g. government agencies, regulatory agencies and the Canadian Commission on Dental Accreditation, to name but a few. Perhaps, HSC has set a precedent that others will aspire to - industry expects, so why not our patients. There are,
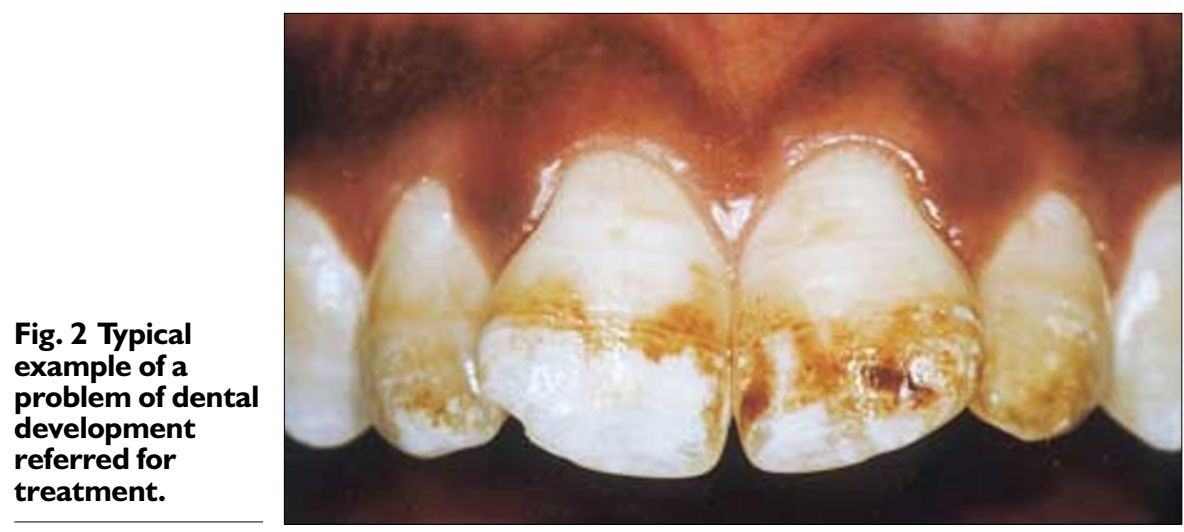

Fig. 3

Radiographic example of oligodontia associated with ectodermal dysplasia.

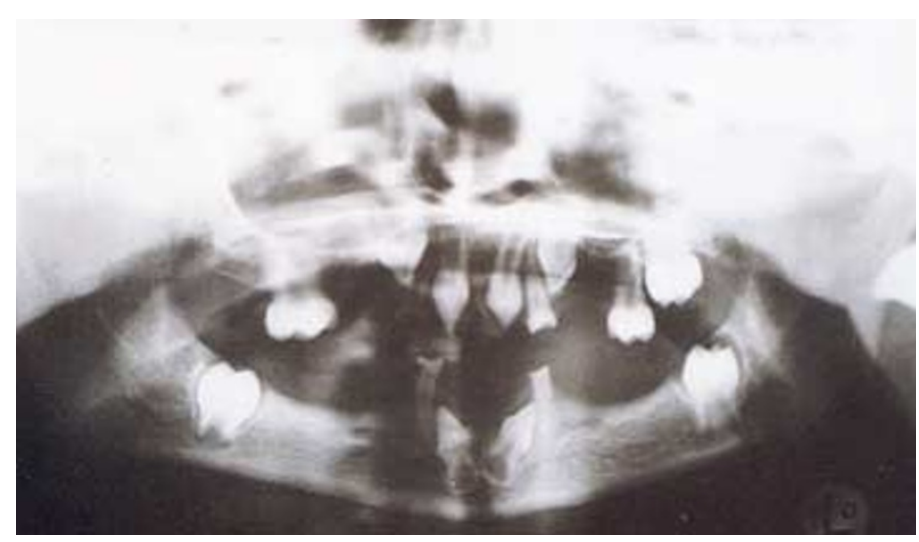

after all, over 30 dental practices in the UK with an ISO award already, and the number of dental practices with Investors in People must be close to 100 .

It is a busy and rapidly changing time for general health care and general dental

\section{The department's} philosophy of total patient care through childhood and into adolescence, as practised in the UK, is something that has to be applauded. health welfare in the UK. Clinical audit, clinical governance, charters, patient welfare and value-for-money seem to be everyday phrases in the ever-expanding medical and dental phraseology textbook. The application and implementation of my experiences whilst in Toronto will hopefully go some way towards me providing a quality service to the NHS.

I would like to thank the British Society for Prosthetic Dentistry for their financial support towards this elective and Dr Carmichael for agreeing to the visitation in the first place.

1 Dentistry Clinic at Sick Kids first in North America to achieve ISO 9002 registration. News release . February 9, 1999.

2 Cleft Lip and Palate. Report of the Clinical Standards Advisory Group. London: HMSO, 1998

3 Kenny D J, Conway R M and Johnston D H.The development of ISO 9002 Quality Management Standards for Canadian Dental Practices. J Can Dent Assoc 1999; 65: 105108. 